that they are sound. The simplest and the best way of doing this would be to stimulate public debate among all professionally interested parties. The recent growth of interest in science policy at the universities shows that the time is ripe. Yet the Council, which is evidently anxious to reconcile the general public (including the Treasury) to the cost of science, is surprisingly cavalier in its apparent assumption that scientists will follow where it leads. Indeed, by assuming that it will usually be for research councils to make detailed decisions on the spending of money, the Council is assuming that the expert advisory committees which decide those things are fully in command of professional opinion. But is this necessarily the case, especially when the proceedings of the committees are in private and not in public? Indeed, unless the Council can set its own methodical and highprincipled stamp on the legion of committees which actually spend money, there is a danger that good management at the top may be accompanied by what seems like arbitrariness lower down.

\section{LONG MEMORIES}

$\mathrm{M}^{\mathrm{n}}$ R. HAAKON CHEVALIER has undermined a strong caso with his book Oppenheimer-The Story of a Friendship (Deutsch, London, 25s.). The objective is an account of the relationship between $\mathrm{Mr}$. Chevalier and Dr. Robert Oppenheimer when Mr. Chevalier was a professor of French at Berkeley and when Dr. Oppenheimer had not yet become the director at Los Alamos. The period was significant for both parties because it provided the raw material on which Oppenheimer later compromised Chevalier with the security authorities in the United States. Mr. Chevalier's subtitle is, of course, ironical.

By now the story of this shabby incident is a part of folk-lore. It was first brought into the open in 1954 when the Personnel Security Board of the U.S. Atomic Energy Commission examined in public the reasons why it should or should not grant a security clearance to Dr. Oppenheimer, the head of the Institute of Advanced Studies at Princeton and then a principal consultant to the Atomic Fnergy Commission. In the course of the evidence it emerged that Chevalier had informed Oppenheimer of a suspicious attempt to obtain secret information in the early years of the Second World War. Oppenheimer retailed this tale to the security people incorrectly. As he put it himself, he told a "cock and bull story". One consequence was to compromise Chevalier and his career. What surprised the hearings in Washington in 1954, and what rankles with Chevalier, is that Oppenheiner did not take steps to make good the damage done.

All this is now part of the public record, and a small part of the poignant history of Oppenheimer's security clearance. Chovalier's book has nothing new to say. Bitter accusations were predictable, but the result is frequently a form of words too unreflective to be communicative. Chevalier tells his tale without much feeling for the emotions concernod-even his own. Whon ho might have thrown light on the character of his relationship with Oppenheimer, or on the tenor of their political discussions, he tends to write about the salad they had for dinner. The result is that his attempt to analyse Oppenheimer's personality reads like a briefing for a puppet show. Chevalier may feel better for having written his book, but few of his readers will be edified.

\section{MALAISE OF CULTURE}

\section{Science and Culture}

A Study of Cohesive and Disjunctive Forces. Edited by Prof. Gerald Holton. (The Daedalus Library, Vol. 4.) Pp. xxxiii +348. (Boston, Mass.: Houghton Mifflin aund Company, 1965.) 6 dollars.

$\mathrm{E}$ VERYONE knows that the worid is out of joint, but not everyone takes this to heart so much as the physieists, whose brainchild, the bomb, has brought them a profound sense of guilt. What has gone wrong? Is it nothing more than an estrangement between C. P. Snow's 'Two Cultures'? Or has seience run amok and technology gone berserk? Is culture suffering from a degenerative disease called 'applied science'? Or, on the contrary, is it precisely this that we so desperately need, namely, a universal acceleration of the pace of scientific advance, which alone can triumph over the hydrogen bomb, overpopulation, and the gap between affluence and poverty? Such soul-searchings led Gerald Holton, professor of physics at Harvard, with fourteen co-authors, among them Harvey Brooks, R. Dubos, H. Marcuse, D. K. Price and $\mathrm{E}$. Weil, to reflect on the mutual relationships of science and culture in the world of to-day.

Their contributions fall into three sections. The first: is concerned with definitions and history. The second. more provocatively, deals with elements making for cultural coherence, and the third comes to grips with elements making for disjunction and alienation.

The second section opens with a study of the diffusion of basic eoncepts from one science to another, and from science to the arts and humanities. Thus the images and vocabulary of chemical equilibrium theory constantly recur in descriptions of social and economic phenomena; the idea of relativity has spread from physics to anthropology, psychology and history; and the notions of feedback and information are common to many disciplines in which 'environment' is equated with 'input' and decision with 'output'. Furthermore, there is a general acceptance that the observer interacts with the system under observation, whether the system be physical, historical or political. And there is a parallel between the abstract world picture provided by physics and the trend to abstraction in modern art and poetry, a parallel which contemporary representatives of optical and kinetic art, such as J. R. Soto, would no doubt warmly endorse. These reflexions lead Prof. Brooks to ask whether a psychologist, by studying present-day tastes in poetry, could predict the kind of theories likely to be acceptable in elementary particle physics, or vice versa.

In the same section Prof. Holton develops his challenging thesis that when one looks closely at the manner in which scientific hypotheses are initially formed, tested, and accepted or rejected, the alleged duality of culture seems to vanish. A three-dimensional propositional space, he suggests, may be used to chart the components of a scientific theory: the $x$-axis for empirical data, the $y$-axis for the analytical-heuristic dimension, and the $z$-axis for the thematic component-that which is rooted outside science.

Gloomy thonghts begin to emerge in the third section: modern science is an ally of a monstrous technology that threatens man's existence; and it is the growth medium of an equally monstrous ideology that engulfs the life of the mind. In the United States, we are told, the means of society are unrelated to its professed ends. American eulture, because of the "permanent mobilization of the people for the eventuality of nuclear war", is swallowed by civilization. As a result, education for intellectual and emotional independence is "an all but subversive programme which involves violation of some of the strongest democratic taboos".

A number of contributors are profoundly critical of the establishment. They urge us to specify the criteria 